\title{
A CRITICAL ASSESSMENT OF THE FREEZE-DRIED DISC TECHNIQUE FOR DETERMINING THE SENSITIVITY OF BACTERIA TO SULPHONAMIDES AND ANTIBIOTICS
}

\author{
BY \\ C. E. D. TAYLOR, G. V. HEIMER, AND C. C. SPICER \\ From the Routine Diagnostic Laboratory and the Epidemiological Research Laboratory, \\ Central Public Health Laboratory, Colindale, London
}

(RECEIVED FOR PUBLICATION JANUARY 9, 1958)

Of the many methods employed for determining the sensitivity of bacteria to antibiotics and sulphonamides, the use of impregnated blotting paper discs has a number of advantages.

It has been pointed out, however, that there are many sources of error in the disc technique, that irregular results are not uncommon, and that the potencies of commercially prepared discs are not always in accordance with their labelled claims (Fairbrother and Martyn, 1951 ; Greenberg, Fitzpatrick, and Branch, 1957).

In view of such criticisms, an assessment of the reproducibility and reliability of the technique carried out in this laboratory was undertaken in order to define the limits of accuracy of routine tests, and to determine the effects of storage on materials employed.

The present investigation shows that discs dried under suitable conditions can be prepared in bulk and stored for relatively long periods without significant loss of potency, and that the amount of test substance per disc can be accurately controlled. Moreover, a high degree of reproducibility of results can be obtained.

\section{Materials and Methods}

Preparation of Freeze-dried Discs.-Discs, $5 \mathrm{~mm}$. in diameter, were cut from Ford 428 mill coloured blotting paper, and an arbitrary colour was allocated to each test substance for ease of identification (Bowie and Gould, 1952). After sterilizing, each disc was impregnated with a standard drop $(0.02 \mathrm{ml}$.) of a standard solution of test substance appropriate to the colour of the disc. The discs were then snap freezedried in a freeze-drying apparatus (Edwards, Model 3P). Finally, the dried discs were transferred to open-topped glass containers which were stored at $+4^{\circ} \mathrm{C}$. over anhydrous calcium chloride in outer glass containers fitted with screw caps, and containing a few granules of silica gel to indicate by their colour the prevailing state of desiccation.

Concentrations of Test Substances.-The following concentrations were employed. They are similar to those used by Fairbrother and Martyn (1951).

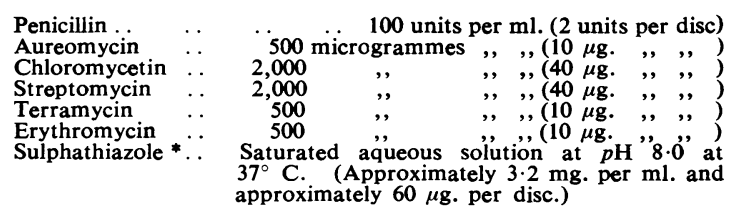

Medium.-Many batches of nutrient media contain a sulphonamide antagonist. This difficulty may be overcome by the incorporation of lysed blood in the medium (Harper and Cawston, 1945; Walker, Philip, Smyth. and McLeod, 1947). Petri dishes, $15 \mathrm{~cm}$. in diameter, were employed, containing "oxoid" blood agar base with the addition of $5 \%$ defibrinated horse blood previously lysed by freezing and thawing. Care was taken to maintain uniformity in the thickness of the medium in the plates, since variations affect the size of inhibition zones.

Standard Strain of Staphylococcus pyogenes. - A strain of Staphylococcus pyogenes (N.C.T.C. No. 6571) was used as the test organism throughout.

Size of Inoculum.-The inoculum was standardized to give discrete colonies after 18 hours' incubation at $37^{\circ} \mathrm{C}$.

Application of Discs.-Discs were applied by means of sterile forceps to the surface of each agar plate in such a manner that they were evenly distributed, and were firmly adherent. They were sufficiently far apart to prevent synergism and antagonism between antibiotics.

Reading of Plates.-After 18 hours' incubation at $37^{\circ}$ C., diameters of zones of inhibition were measured in millimetres and recorded.

* For convenience, sulphathiazole will be included as an antibiotic hereafter. 


\section{Experimental Results}

Reproducibility of Tests Using Different Batches of Medium.-Experiments were carried out using the methods described above to provide information on the total error of sensitivity testing, and also on some of the components of this error, such as those arising from the variations in media, differences between plates, and differences between the readings made by separate observers.

TABLE I

RESULTS OF STATISTICAL ANALYSIS OF SOURCES OF ERROR

\begin{tabular}{|c|c|c|c|c|c|c|}
\hline & & $\mathbf{A}$ & B & $\mathrm{C}$ & D & $\mathbf{E}$ \\
\hline $\begin{array}{l}\text { Terramycin } \\
\text { Penicillin . } \\
\text { Streptomycin } \\
\text { Aureomycin } \\
\text { Chloromycetin } \\
\text { Erythromycin } \\
\text { Sulphathiazole }\end{array}$ & $\begin{array}{l}\cdots \\
\cdots \\
\cdots \\
\cdots \\
\cdots \\
\cdots\end{array}$ & $\begin{array}{l}0.692 \\
1.314 \\
0.665 \\
0.649 \\
0.795 \\
0.111 \\
4 \cdot 240\end{array}$ & $\begin{array}{l}5.08 \\
0 \cdot 219 \\
0.055 \\
1 \cdot 290 \\
0.087 \\
0 \cdot 129 \\
0.288\end{array}$ & $\begin{array}{l}0.286 \\
0.055 \\
0.219 \\
0.312 \\
0.246 \\
0.670 \\
0.560\end{array}$ & $\begin{array}{l}0.586 \\
0.522 \\
0.127 \\
0.480 \\
0.859 \\
0.296 \\
0.680\end{array}$ & $\begin{array}{l}2.57 \\
1.45 \\
1.03 \\
1.65 \\
1.31 \\
1.10 \\
2.40\end{array}$ \\
\hline
\end{tabular}

The results of a statistical analysis of these sources of error are summarized in Table I, the methods of analysis being described in the Appendix. (The figures are mean square errors in $\mathrm{mm} .{ }^{2}$, except for column $\mathrm{E}$, which gives the total root mean square error in $\mathrm{mm}$.) The column headings have the following meanings:

A. Errors in Repetitions of Same Test on Different Days.--These would arise mainly from variations in the batches of medium and it can be seen that sulphathiazole is outstandingly variable in this respect, as is to be expected owing to the difficulty of neutralizing the sulphonamide inhibitors.

B. Errors from Differences Between Measurements Recorded by Different Observers on Same Plate.-Aureomycin and terramycin are particularly affected by this kind of error, suggesting that with each there is a strong subjective element in determining the boundary of the zone of inhibition.

C. Errors Due to Differences Between Plates Read on Same Day and with Same Batch of Medium.-All the antibiotics are about equally affected by errors of this kind.

D. Error Found in Comparing Readings by Same Observer on Repetitions of a Test on Same Plate.-The accuracy of the assay was about the same for all the antibiotics in this respect.

E. Total Standard Error of Readings Affected by All Sources of Error in Previous Columns. This has been calculated from the square root of the sum of the other entries in the same line. It appears from these figures that all the sensitivity measurements made by the present method are reasonably consistent even when made under the most unfavourable conditions. The range of variations in diameter of the zone of inhibition is from 2 to $5 \mathrm{~mm}$., which, with the sizes of zones considered, represents an error of about $10 \%$.

Possible Effect on Sensitivity Tests of Changes in Strain of Organisms During an Experiment.Two strains of staphylocosci were tested in parallel at intervals over a period of four weeks for their sensitivity to penicillin and sulphathiazole. One strain was the standard strain (N.C.T.C. No. $6571)$; the other was a relatively resistant strain. One plate was set up for each organism and each antibiotic, and five discs were put on to each plate. The differences between the means of the five diameters on each plate did not vary by more than $1.5 \mathrm{~mm}$. for the penicillin tests, or by more than $2 \mathrm{~mm}$. for sulphathiazole during the course of the experiment, which represents an accuracy of approximately $10 \%$. Readings were made by the same observer throughout, so that one source of inaccuracy was eliminated. The figures given above, however, show that the differences between observers are small for these two antibiotics, and that the introduction of this source of error would not have seriously altered the results.

A more detailed statistical analysis shows that there was no significant variation in the relative sensitivity of the two strains during the period of testing, though there was possibly a tendency for the differences in sulphathiazole sensitivity to diminish as time went on. The values of the differences in diameter of inhibition zones for the two antibiotics are shown in Table II.

TABLE II

DIFFERENCES OF MEAN ZONE DIAMETERS (MM.) BETWEEN A TEST AND STANDARD STRAINS AT INTERVALS FOR FOUR WEEKS

\begin{tabular}{c|c|c}
\hline Date & Pe ricillin & Sulpha:hiazole \\
\hline 30.557 & $16 \cdot 6$ & $7 \cdot 2$ \\
$56 / 57$ & $16 \cdot 0$ & $7 \cdot 6$ \\
$136 / 57$ & $16 \cdot 2$ & $6 \cdot 2$ \\
$18,6 / 57$ & $15 \cdot 6$ & $6 \cdot 2$ \\
$25,6 / 57$ & $16 \cdot 8$ & $5 \cdot 8$ \\
\hline
\end{tabular}

Effect of Storage on Freeze-dried Discs.-Discs were tested at the beginning and end of batches in routine daily use. The results are summarized in Table III. The second column indicates the time at the beginning and end of which each batch was tested. Apart from sulphathiazole the changes in potency were small. The apparent increase in potency of the sulphathiazole discs was almost 
TABLE III

EFFECT OF STORAGE ON FREEZE-DRIED DISCS

\begin{tabular}{|c|c|c|c|c|}
\hline Antibiotic & $\begin{array}{c}\text { Time } \\
\text { (Weeks) }\end{array}$ & $\begin{array}{c}\text { Difference } \\
\pm \text { Error }\end{array}$ & Change & $\begin{array}{c}\text { Significance } \\
\text { Level }\end{array}$ \\
\hline $\begin{array}{ll}\text { Lureomycin } & \ldots \\
\text { erramycin } & \ldots \\
\text { Chloromycetin } & . . \\
\text { treptomycin } & \ldots \\
\text { ilphathiazole } & \ldots \\
\text { enicillin } & \ldots \\
\text { irythromycin } & \ldots\end{array}$ & $\begin{array}{l}30 \\
23 \\
25 \\
36 \\
28 \\
25 \\
44\end{array}$ & $\begin{array}{l}-1.60 \pm 0.19 \\
-1.56 \pm 0.2 \\
-0.18 \pm 0.31 \\
-0.38 \pm 0.15 \\
+3.48 \pm 0.20 \\
-0.42 \pm 0.25 \\
-0.70 \pm 0.27\end{array}$ & $\begin{array}{r}-5.8 \\
-5.6 \\
-0.6 \\
-1.5 \\
+15.6 \\
-1.4 \\
-2.3\end{array}$ & $\begin{array}{c}<0.001 \\
<0.001 \\
0.60 \\
0.02-0.01 \\
<0.001 \\
0.1-0.05 \\
0.01-0.001\end{array}$ \\
\hline
\end{tabular}

Difference $=($ mean diameter at first test - mean diameter at second test).

certainly due to the presence of a smaller amount of sulphonamide antagonist in the medium when the second test was carried out.

Relation Between Diameter of Inhibition Zone and Antibiotic Sensitivity in the Disc Technique.The relationship between the diameter of the zone of inhibition and the actual sensitivity of the organism is not simple. Using the theoretical treatment of the formation of inhibition zones put forward by Humphrey and Lightbown (1952), it is possible to relate the diameter to the sensitivity and provide a rather more satisfactory classification of resistant strains than arbitrary subdivision in terms of diameters. Their analysis

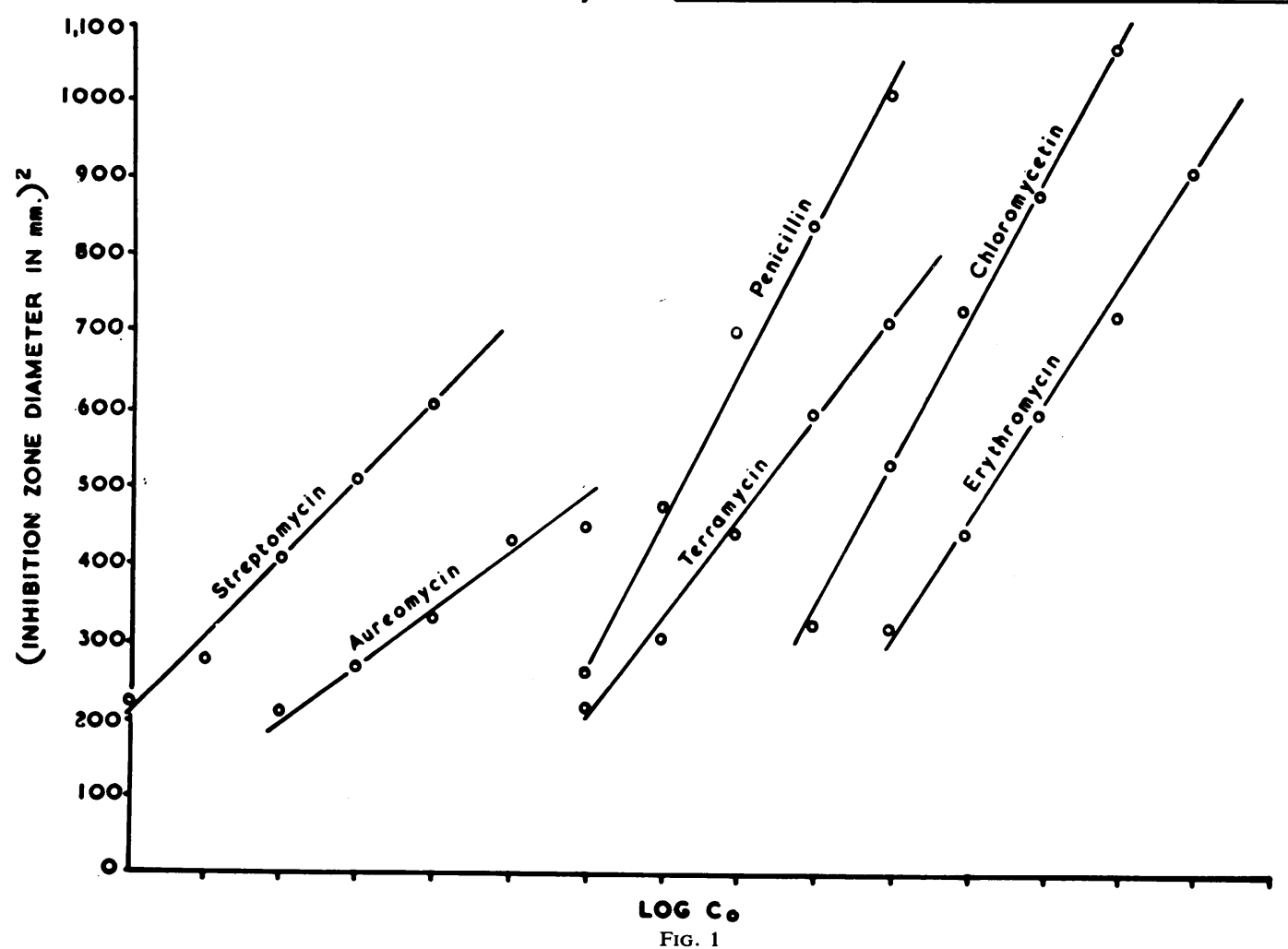

suggests that there should be a linear increase in the squares of the zone diameters of a given strain exposed to discs containing logarithmically increasing quantities of antibiotic.

This has been tested on the standard strain for all antibiotics mentioned above except sulphathiazole, and the results are shown in Fig. 1.

The straight line relation is quite closely verified, and, using the values of slopes for the different antibiotics, the expected differences between the diameters of the inhibition zones of the standard strain and others, two, five, and 10 times as resistant were calsulated, and are shown in Table IV.

TABLE IV

THEORETICAL DIFFERENCE IN DIAMETER (MM.) OF INHIBITION ZONE BETWEEN A STANDARD SENSITIVE STRAIN AND STRAINS OF $2 \times, 5 \times$, AND $10 \times$ RELATIVE RESISTAN̉CE

\begin{tabular}{|c|c|c|c|c|c|c|}
\hline \multirow{2}{*}{\multicolumn{3}{|c|}{ Antibiotic }} & \multicolumn{3}{|c|}{ Differences } & \multirow{2}{*}{ b } \\
\hline & & & $S=2$ & 5 & 10 & \\
\hline $\begin{array}{l}\text { Aureomycin ... } \\
\text { Chloromycetin } \\
\text { Erythromycin } \\
\text { Penicillin } \\
\text { Streptomycin } \\
\text { Terramycin .. }\end{array}$ & $\begin{array}{l}\cdots \\
\cdots \\
\cdots \\
\cdots\end{array}$ & $\begin{array}{l}\cdots \\
\cdots \\
\cdots \\
\cdots\end{array}$ & $\begin{array}{l}2 \\
3 \\
3 \\
3 \\
2 \\
2\end{array}$ & $\begin{array}{l}4 \\
8 \\
7 \\
8 \\
5 \\
6\end{array}$ & $\begin{array}{r}7 \\
11 \\
10 \\
12 \\
8 \\
9\end{array}$ & $\begin{array}{l}100 \\
256 \\
217 \\
269 \\
144 \\
184\end{array}$ \\
\hline
\end{tabular}


Referring to Table I column E, it can be seen that a twofold difference in sensitivity is not generally detectable within the limits of error of the test, fivefold is just detectable, and tenfold easily detectable.

On the basis of these experiments, it seems reasonable to classify the resistance of naturally occurring strains according to zone diameters as follows.

(1) Up to five times resistant ..

Sensitive

(2) More than five times resistant but not more than 10 times resistant .

Partially sensitive

\section{(3) More than 10 times resistant Resistant}

The diameters of inhibition zones should be determined for the standard strain concurrently with each batch of sensitivity tests, or for each batch of medium.

It is felt that a direct classification in terms of resistance is of more help clinically than one in terms of zone diameter.

\section{Summary}

A technique for assessing antibiotic sensitivities using freeze-dried blotting-paper discs is described. This technique has been shown to be highly accurate and reproducible.

Test strains can be quantitatively compared with a standard strain or with one another, and an attempt has been made to relate the diameter of the inhibition zones to the true sensitivity of the organism.

It is suggested that the resistance of naturally occurring strains might be classified on the basis of sensitivity rather than on the diameter of the inhibition zone.

We are most grateful to Dr. S. T. Cowan, Curator of the National Collection of Type Cultures, for granting facilities for the freeze-drying of antibiotic discs, and for providing the strain of Staphylococcus pyogenes used as a standard.

Also we thank Dr. R. E. O. Williams, Director of the Staphylococcal Reference Laboratory, for advice during the course of this work, and Mr. P. J. Fisher, who was in charge of the freeze-drying operations.

\section{A P P E N D I X}

The various sources of error in the sensitivity tests were investigated by the usual analysis of variance techniques (see, for example, Snedecor, 1946). The components of variation due to differences between observers and to day-to-day variations in the test were investigated in two separate experiments, and so the interactions between them were not measured. However, the estimates of error arising from the sources given in Table I would not be seriously disturbed by this, and a general figure of about 1 to $2 \mathrm{~mm}$. for the standard error and $4 \mathrm{~mm}$. for the likely range of variation can be applied to all the antibiotics considered. There is, in addition, an error of grouping, since the diameters were read only to the nearest millimetre. A correction for this would reduce the standard deviation of a reading slightly but has not been made since it cannot be incorporated in tests of significance and it seems better to work with an upper rather than a lower limit of error.

The general plan of the tests was to use five plates for each source of variation, e.g., observer or day, and to have five discs on each plate. The final results give the mean square errors for each component and are estimated from the corresponding line in an analysis of variance table. The process is best explained by an example, and for this purpose we may take the experiments on chloromycetin, which are summarized in Table $\mathrm{Va}$ and $\mathrm{b}$. The first table gives the results of an experiment in which sensitivity tests were repeated on the same strain by the same observer on different days.

TABle Va

CHLOROMYCETIN

\begin{tabular}{|c|c|c|c|c|}
\hline 181155 & 21255 & 161255 & 20156 & 3256 \\
\hline $\begin{array}{l}30 \\
30 \\
28 \\
28 \\
31 \\
\bar{x}=29 \cdot 4\end{array}$ & $\begin{array}{l}30 \\
29 \\
29 \\
30 \\
29 \\
\bar{x}=29 \cdot 4\end{array}$ & $\begin{array}{l}31 \\
30 \\
30 \\
32 \\
31 \\
\bar{x}-30 \cdot 8\end{array}$ & $\begin{array}{l}30 \\
30 \\
30 \\
30 \\
30 \\
\bar{x}=30 \cdot 0\end{array}$ & $\begin{array}{l}30 \\
31 \\
32 \\
32 \\
33 \\
\bar{x}=31 \cdot 6\end{array}$ \\
\hline $\begin{array}{l}28 \\
28 \\
30 \\
31 \\
32 \\
\bar{x}=29 \cdot 8\end{array}$ & $\begin{array}{l}30 \\
30 \\
29 \\
29 \\
30 \\
\bar{x}-29 \cdot 6\end{array}$ & $\begin{array}{l}30 \\
30 \\
30 \\
32 \\
30 \\
\bar{x}=30 \cdot 4\end{array}$ & $\begin{array}{l}30 \\
30 \\
30 \\
30 \\
30 \\
\overline{\mathrm{x}}=30 \cdot 0\end{array}$ & $\begin{array}{l}32 \\
30 \\
31 \\
32 \\
31 \\
\bar{x}=31 \cdot 2\end{array}$ \\
\hline $\begin{array}{l}28 \\
32 \\
30 \\
30 \\
30 \\
\bar{x}=30 \cdot 0\end{array}$ & $\begin{array}{l}29 \\
30 \\
30 \\
29 \\
30 \\
\bar{x}=29 \cdot 4\end{array}$ & $\begin{array}{l}30 \\
31 \\
32 \\
31 \\
32 \\
\bar{x}=31 \cdot 2\end{array}$ & $\begin{array}{l}31 \\
31 \\
30 \\
31 \\
31 \\
\bar{x}=30 \cdot 8\end{array}$ & $\begin{array}{l}30 \\
32 \\
30 \\
30 \\
31 \\
\bar{x}=30.6\end{array}$ \\
\hline $\begin{array}{l}28 \\
30 \\
32 \\
32 \\
28 \\
\bar{x}=30 \cdot 0\end{array}$ & $\begin{array}{l}27 \\
27 \\
27 \\
27 \\
27 \\
\bar{x}=27 \cdot 0\end{array}$ & $\begin{array}{l}32 \\
32 \\
32 \\
31 \\
32 \\
\bar{x}=31 \cdot 8\end{array}$ & $\begin{array}{l}31 \\
31 \\
31 \\
31 \\
30 \\
\bar{x}=30 \cdot 8\end{array}$ & $\begin{array}{l}30 \\
31 \\
31 \\
31 \\
32 \\
\bar{x}=31 \cdot 0\end{array}$ \\
\hline $\begin{array}{l}28 \\
30 \\
32 \\
30 \\
28 \\
\overline{\mathrm{x}}=29 \cdot 6\end{array}$ & $\begin{array}{l}30 \\
27 \\
28 \\
27 \\
28 \\
\overline{\mathrm{x}}=\mathbf{2 8} \cdot 0\end{array}$ & $\begin{array}{l}30 \\
30 \\
32 \\
30 \\
30 \\
\bar{x}=3 \mathrm{C} \cdot 4\end{array}$ & $\begin{array}{l}30 \\
30 \\
31 \\
31 \\
31 \\
\overline{\mathrm{x}}=30 \cdot 6\end{array}$ & $\begin{array}{l}31 \\
30 \\
30 \\
30 \\
31 \\
\overline{\mathbf{x}}=30.4\end{array}$ \\
\hline $\bar{X}=29 \cdot 8$ & $\mathrm{X}=29 \cdot 1$ & $\bar{x}=30.9$ & $\bar{X}=30.4$ & $\bar{X}=30.9$ \\
\hline
\end{tabular}


TABLE Vb

CHLOROMYCETIN

\begin{tabular}{|c|c|c|c|c|c|}
\hline \multirow{2}{*}{ Plate } & \multicolumn{5}{|c|}{ Observers } \\
\hline & $\boldsymbol{G}$ & $M$ & $P$ & $T$ & $\boldsymbol{H}$ \\
\hline $\mathbf{A}$ & $\begin{array}{l}30 \\
30 \\
30 \\
30 \\
29 \\
\overline{\mathrm{x}}=29 \cdot 8\end{array}$ & $\begin{array}{l}27 \\
29 \\
29 \\
30 \\
29 \\
\overline{\mathrm{x}}=28.8\end{array}$ & $\begin{array}{l}30 \\
30 \\
29 \\
30 \\
31 \\
\overline{\mathrm{x}}=30 \cdot 0\end{array}$ & $\begin{array}{l}28 \\
27 \\
28 \\
27 \\
30 \\
\overline{\mathbf{x}}=28 \cdot 0\end{array}$ & $\begin{array}{l}29 \\
29 \\
29 \\
29 \\
30 \\
\overline{\mathbf{x}}=29 \cdot 2\end{array}$ \\
\hline B & $\begin{array}{l}31 \\
30 \\
30 \\
30 \\
30 \\
\bar{x}=30 \cdot 2\end{array}$ & $\begin{array}{l}29 \\
29 \\
31 \\
30 \\
29 \\
\vec{x}=29 \cdot 6\end{array}$ & $\begin{array}{l}30 \\
31 \\
31 \\
30 \\
31 \\
\overline{\mathrm{x}}=30 \cdot 6\end{array}$ & $\begin{array}{l}29 \\
30 \\
28 \\
30 \\
30 \\
\bar{x}=29 \cdot 4\end{array}$ & $\begin{array}{l}29 \\
30 \\
30 \\
30 \\
31 \\
\bar{x}=30 \cdot 0\end{array}$ \\
\hline C & $\begin{array}{l}31 \\
31 \\
31 \\
31 \\
32 \\
\overline{\mathbf{x}}=31 \cdot 2\end{array}$ & $\begin{array}{l}30 \\
30 \\
31 \\
30 \\
30 \\
\overline{\mathrm{x}}=30 \cdot 2\end{array}$ & $\begin{array}{l}31 \\
30 \\
32 \\
30 \\
30 \\
\overline{\mathrm{x}}=30 \cdot 6\end{array}$ & $\begin{array}{l}32 \\
31 \\
29 \\
30 \\
32 \\
\overline{\mathrm{x}}=30.8\end{array}$ & $\begin{array}{l}28 \\
30 \\
30 \\
30 \\
30 \\
\overline{\mathrm{x}}=29.6\end{array}$ \\
\hline D & $\begin{array}{l}30 \\
30 \\
30 \\
30 \\
31 \\
\overrightarrow{\mathbf{x}}=30 \cdot 2\end{array}$ & $\begin{array}{l}30 \\
29 \\
30 \\
32 \\
32 \\
\overline{\mathrm{x}}=30 \cdot 6\end{array}$ & $\begin{array}{l}30 \\
32 \\
30 \\
31 \\
30 \\
\bar{x}=30 \cdot 6\end{array}$ & $\begin{array}{l}32 \\
33 \\
30 \\
32 \\
32 \\
\bar{x}=31 \cdot 8\end{array}$ & $\begin{array}{l}29 \\
30 \\
30 \\
30 \\
30 \\
\bar{x}=29.8\end{array}$ \\
\hline E & $\begin{array}{l}29 \\
31 \\
30 \\
30 \\
30 \\
\overline{\mathrm{x}}=30 \cdot 0\end{array}$ & $\begin{array}{l}29 \\
30 \\
29 \\
30 \\
29 \\
\bar{x}=29 \cdot 4\end{array}$ & $\begin{array}{l}29 \\
29 \\
30 \\
30 \\
29 \\
\bar{x}=29 \cdot 4\end{array}$ & $\begin{array}{l}32 \\
33 \\
32 \\
29 \\
29 \\
\bar{x}=31 \cdot 0\end{array}$ & $\begin{array}{l}28 \\
28 \\
27 \\
28 \\
27 \\
\bar{x}=27 \cdot 6\end{array}$ \\
\hline & $\bar{X}=30 \cdot 3$ & $\mathrm{X}=29 \cdot 7$ & $X=30 \cdot 2$ & $X=30 \cdot 2$ & $\mathrm{X}=29 \cdot 2$ \\
\hline
\end{tabular}

The analysis of variance for this experiment is as follows :

\begin{tabular}{|c|c|c|c|}
\hline & $\begin{array}{l}\text { Sum of } \\
\text { Squares }\end{array}$ & D.F. & $\begin{array}{c}\text { Mean } \\
\text { Square }\end{array}$ \\
\hline $\begin{array}{l}\text { Between days } \ldots \\
\text { Between plates on the same day } \\
\text { Residual errors .. }\end{array}$ & $\begin{array}{l}88 \cdot 24 \\
43 \cdot 76 \\
95 \cdot 80\end{array}$ & $\begin{array}{r}4 \\
20 \\
100\end{array}$ & $\begin{array}{r}22 \cdot 060 \\
2 \cdot 188 \\
0 \cdot 958\end{array}$ \\
\hline
\end{tabular}

The second table gives the results for an experiment in which the same set of five plates was read by different observers. The analysis of variance is:

\begin{tabular}{lll|l|r|r}
\hline Between observers & $\ldots$ & $\ldots$ & 20.288 & 4 & 5.072 \\
Between plates . & $\ldots$ & $\ldots$ & 36.688 & 4 & 9.672 \\
Observor and plate interaction & 46.512 & 16 & 2.907 \\
Residual errors .. & $\ldots$ & $\ldots$ & 76.000 & 100 & 0.760 \\
\hline
\end{tabular}

From the first table the error due to differences between tests made on different days is (22.0602.188) $/ 25=0.795$, and that due to differences between plates $(2.188-0.958) / 5=0.246$.

The second table gives an estimate of the error arising in readings made by different observers on the same plate. This is calculated as $(5.072-2.907) / 25=$ 0.0866. An approximate estimate of the plate errors can also be made as $(9.672-2.907) / 25=0.271$, which compares well with the value 0.246 found in the first experiment. The residual errors, 0.958 and 0.760 , are also in reasonable agreement, and do not differ significantly.

\section{REFERENCES}

Bowie, J. H., and Gould, J. C. (1952). J. clin. Path., 5, 356.

Fairbrother, R. W., and Martyn, G. (1951). Ibid., 4, 374.

Greenberg, L., Fitzpatrick, K. M., and Branch, A. (1957). Canad. med. Ass. J., 76, 194.

Harper, G. J., and Cawston, W. C. (1945). J. Path. Bact., 57, 59.

Humphrey, J. H., and Lightbown, J. W. (1952). J. gen. Microbiol., 7, 129.

Snedecor, G. W. (1946). Statistical Methods, 4th ed. Iowa.

Walker, N., Philip, R. P., Smyth, M. W., and McLeod, J. W. (1947). J. Path. Bact., 59, 631 . 